\title{
Diffraction Radiation Oscillator with Asymmetric Open Resonant System. Part I. Cold Test Results of Open Resonant System
}

\author{
V.S. Miroshnichenko*, I.O. Kovalov \\ O.Ya. Usikov Institute for Radiophysics and Electronics NAS of Ukraine \\ 12, Akad. Proskury Sr., 61085 Kharkiv, Ukraine
}

(Received 04 April 2016; revised manuscript received 09 June 2016; published online 21 June 2016)

\begin{abstract}
The results of experimental investigations and 2-D modeling of asymmetric open resonant system properties for diffraction radiation oscillator, in which the periodic structure is displaced on the field spot periphery of operating TEM $_{00 \text { q }}$-mode, are presented. It was established, that the asymmetric placement of the periodic structure, in double grating form, on the flat mirror of hemispherical open resonator allows to reduce ohmic and diffraction loss of operating TEM $_{00 \mathrm{q}}$-mode and significantly extend the bandwidth of the single-mode tuning. The investigations are carried out in 8-mm waveband.
\end{abstract}

Keywords: Open resonant system, Diffraction radiation oscillator, Periodic structure, Double grating, Millimeter waves.

DOI: 10.21272/jnep.8(2).02033

PACS numbers: 84.40.Fe, 85.40.Bh, 42.82.Bg

\section{INTRODUCTION}

Traditionally in diffraction radiation oscillators (DRO) to obtain interaction between electron beam and open resonant system (ORS), the periodic structure in form of reflecting diffraction grating is used, which has a quarter-wave slot depth and is located in the centre of flat or cylindrical mirror $[1,2]$. Limited by the width the reflecting grating makes a strong perturbation to resonant field structure, so the phase matching between reflecting grating and operating mode field in wide-band frequency was given much attention [3-6]. Features of the energy exchange in DRO with reflecting diffraction grating, which is asymmetrically located on the ORS mirror (the grating is shifted along the electron beam motion), were considered theoretically in linear [7] and non-linear regimes [8] in assumption, that the grating shift doesn't change the resonant field structure and ORS Q-factor.

The usage of the double grating allowed to increase the using of ribbon electron beam through its thickness and significantly to increase the efficiency and output power of DRO [9]. On the optimum operating frequency the double grating with "half-wave" height along ORS longitudinal axis practically doesn't perturb the resonant field structure that makes possible usage the fundamental $\mathrm{TEM}_{00 \mathrm{q}}$-mode with small diffraction loss as operating mode in DRO. The undesirable disadvantage of DRO with a double grating is the small frequency tuning range, which is caused by abrupt change of the resonant field structure in ORS at detuning from the optimal operating frequency. To extend the DRO tuning range earlier was offered the ORS with "transparent" double grating [10], in which the frequency tuning range was increased due to symmetrical placement of double grating in standing wave field between ORS mirrors. Another way to extend the frequency tuning range has been implemented in DRO-orbictron, where the double grating was placed on the rectangular groove bottom, which played a role of a matching trans- former between double grating field and ORS resonant mode $[11,12]$.

In the present paper to extend the frequency tuning range of DRO and to increase its frequency stability we suggested to use the ORS with asymmetric location of limited by the width double grating on flat mirror, specifically: the double grating is shifted on field spot periphery of operating TEM $_{00 q}$-mode in the perpendicular to electron beam motion direction. Such displacement of the double grating allows to increase the DRO frequency stability by reducing of ohmic loss in the ORS and to extend the frequency tuning range of DRO due to reducing of the double grating influence on resonant field structure. The results of experimental investigations of the operating TEM $_{00 q}$-mode properties in ORS with symmetric and asymmetric double grating placement on the flat mirror, and also the results of $2 \mathrm{D}$ modeling resonant field structure in such ORS are shown in this paper. The investigations were carried out in $8-\mathrm{mm}$ waveband.

\section{PARAMETERS OF ASYMMETRIC ORS AND COLD TEST METHOD}

For experimental investigations the ORS was chosen, which consists of hemispherical open resonator and the double grating placed on the flat mirror and leveled to its surface (Fig. 1). The experimental setup allowed to change the distance $D$ between the mirrors and to shift mirrors in parallel plane along $O X$ axis without alignment distortion, that ensured the double grating shifting to field spot periphery of TEM $\mathrm{TO}_{0 \mathrm{q}}$-mode on the flat mirror. Note, that in the index $q$ for the TEM $_{00 \mathrm{q}}$-mode we include the number of resonant field variation between ORS mirrors along longitudinal axis $(O Z$ axis on Fig. 1) without resonant field in double grating. In the centre of spherical mirror with a circular aperture $\left(R_{s p h}=50 \mathrm{~mm}, \varnothing 55 \mathrm{~mm}\right)$ was made the output port the slot form $0.1 \times 7.2 \mathrm{~mm}^{2}$ with the wedgeshaped transition to standard output waveguide

* mirosh@ire.kharkov.ua 
$3.4 \times 7.2 \mathrm{~mm}^{2}$. The flat mirror with the diameter $2 A=58 \mathrm{~mm}$ was truncated on two sides to $2 B=32 \mathrm{~mm}$ to allocate the electron gun and the collector, when the hot test of DRO with asymmetric ORS will be held. The flat mirror aperture allowed a double grating shifting along $O X$ axis to field spot periphery without significant growth of diffraction loss in ORS. The ORS mirrors and the double grating were made of oxygen-free copper.
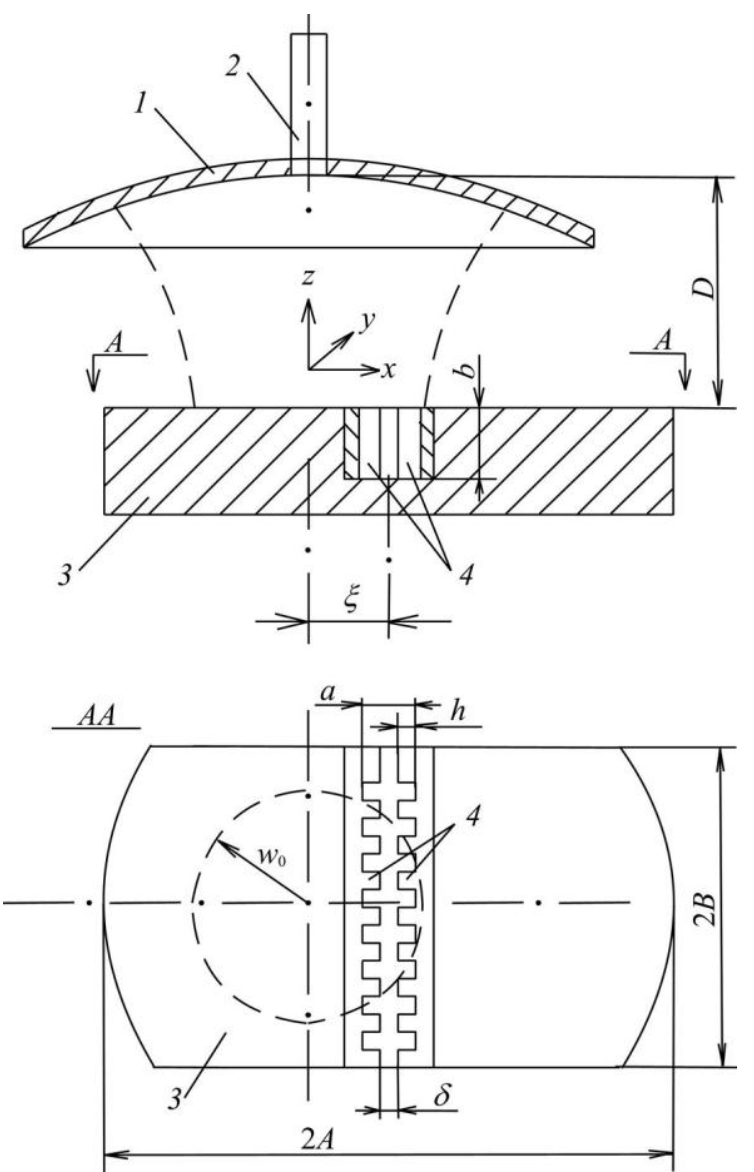

Fig. 1 - Schematic of asymmetric ORS: 1 - spherical mirror; 2 - coupling port; 3 - flat mirror; 4 - double grating

The double grating parameters were: double grating height along $O Z$ axis $-b=8.0 \mathrm{~mm}$; period of the grating $l=1.00 \mathrm{~mm}$; slot width $-d=0.50 \mathrm{~mm}$; slot depth $h=2.56 \mathrm{~mm}$; transit channel width $-\delta=0.30 \mathrm{~mm}$. Selected parameters of the double grating provides the full phase matching between "half-wave" grating and resonant field on frequency $f_{\pi}=33.7 \mathrm{GHz}$ :

$$
f_{\pi}=\frac{c}{2 b} \sqrt{1+\left(\frac{2 b}{\lambda_{c r}}\right)^{2}},
$$

where $c$ is the speed of light, $\lambda_{c r}$ is the critical wavelength of $\mathrm{H}_{10}$-wave in elementary waveguides $d \times a$ (Fig. 1), made by opposite slots of double grating. Note, that due to effect of transit channel the critical wavelength is reduced [13], and for selected parameters of the double grating is: $\lambda_{c r}=1.976 a$.

In the experiment we measured the loaded $\mathrm{Q}$-factor $Q_{L}$ and the coupling coefficient of the ORS $\beta$ on the res- onance curve for the reflection coefficient module $|\Gamma|$ in the output waveguide [14]. The coupling port inserts a negligible reactivity in ORS and the resonant curve for $|\Gamma|$ was almost symmetric, which allowed us to use the results of scalar measurements of reflection coefficient at resonance frequency $\left|\Gamma_{0}\right|$ and at detuning from the resonance frequency $\left|\Gamma_{\mathrm{s}}\right|$. The loaded Q-factor was defined by the resonance curve width $\Delta f$ on the level of $|\Gamma|^{2}=0.5\left(\left|\Gamma_{\mathrm{s}}\right|^{2}+\left|\Gamma_{0}\right|^{2}\right)$ :

$$
Q_{L}=\frac{f_{o}}{\Delta f}
$$

The coupling coefficient $\beta$, when the coupling of ORS to load was lower or higher than the critical value $\left(\beta_{c r}=\left|\Gamma_{\mathrm{s}}\right|\right)$, was determined by (3) and (4):

$$
\begin{aligned}
& \beta=\frac{\left|\Gamma_{s}\right|-\left|\Gamma_{0}\right|}{1+\left|\Gamma_{0}\right|} \text { by } \beta \leq \beta_{c r}, \\
& \beta=\frac{\left|\Gamma_{s}\right|+\left|\Gamma_{0}\right|}{1-\left|\Gamma_{0}\right|} \text { by } \beta>\beta_{c r} .
\end{aligned}
$$

To eliminate the influence of coupling port at the ORS properties comparing by symmetric and asymmetric placement of double grating it was calculated the unloaded Q-factor of ORS from obtained values of $Q_{L}$ and $\beta: Q_{0}=(1+\beta) Q_{L}$.

The distribution of the resonant field $E(x)$ near the flat mirror of the ORS was analyzed by resonant frequency shift, caused by the probe in the conducting sphere form $[15,16]$ :

$$
\frac{f(x)-f_{q}}{f_{q}}=-\frac{r^{3}}{2\left|N_{q}\right|}\left(|\vec{E}(x)|^{2}-\frac{1}{2}|\vec{H}(x)|^{2}\right),
$$

where $f(x)$ is "perturbed" resonance frequency of ORSmode at the probe location on the distance $x$ from the longitudinal axis of the ORS, $f_{q}$ - resonance frequency of the unperturbed ORS-mode, $r$ - the probe radius, $N_{q}-$ ORS-mode norm, which is equal to the doubled stored energy in ORS. The selection of the analysis plane, spaced from the flat mirror surface on $d z=0.25 \lambda$, allowed to minimize the influence of H-component of resonant field on "perturbed" frequency shift.

\section{OPTIMUM DOUBLE GRATING DISPLACE- MENT IN ASYMMETRIC ORS}

The asymmetric placement of periodic structure on the ORS mirror decreases energy exchange intensity between electron beam and resonant field, so it can lead to increasing of oscillation starting current in DRO. On the other hand, in asymmetric ORS the periodic structure influence on the operating mode field reduces, that should decrease a diffraction loss of the operating ORS-mode and to extend frequency tuning range of DRO. As a criterion to choose an optimum shift of periodic structure $\xi$ in asymmetric ORS (Fig. 1) it is possible to take into account the starting current growth in DRO no more than in 1.5 times, followed by essential extending of single-mode frequency tuning range. 
As is known [1], in DRO the oscillation starting current value $I_{s t}$ is defined by interaction space length $L$, by amplitude of electric field on periodic structure $E_{\max }$ and by Q-factor of ORS on operating DRO-mode:

$$
I_{s t} \sim \frac{1}{L^{2} E_{\max }^{2} Q_{0}} .
$$

For fundamental TEMo0q-mode the length of effective interaction space is $L \approx 3 w_{0}$ ( $w_{0}-$ the radius of modes field spot on flat mirror), and it doesn't change by shifting of periodic structure along $O X$ axis to field spot periphery. The decreasing of electric field amplitude by shifting of periodic structure in asymmetric ORS is partially compensated the Q-factor growth due to lowering of the ohmic loss in ORS. If the ohmic loss in periodic structure significantly exceeds other loss of operating mode, it shouldn't be expected essential increasing of oscillation starting current in DRO by using of asymmetric ORS.

It is convenient to carry out a choice of the optimal double grating shift value $\xi$ on frequency $f_{\pi}$, when the double grating doesn't influence on resonant field structure. In the experiment, the choice of optimum displacement $\xi$ for double grating in asymmetric ORS

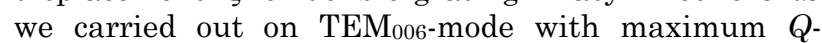
factor for given aperture of ORS mirrors. At the sequential double grating shifting to field spot periphery the monotonic growing of parameters $Q_{L}, \beta$ and $Q_{0}$ for TEMo06-mode was observed (Fig.2). The parameters $Q_{0}$ and $\beta$ were growing in $\sim 3$ times, if the double grating was located at $\xi / w_{0}=1$ (the calculated field spot radius was: $w_{0}=8.37 \mathrm{~mm}$ ).

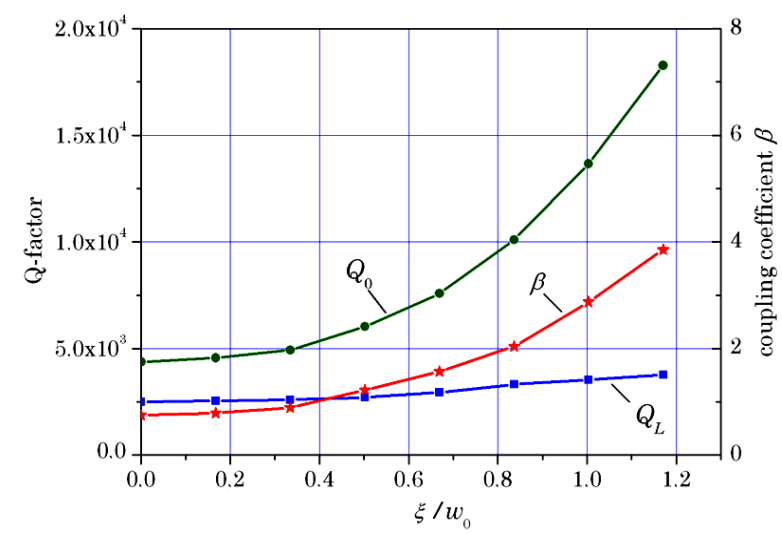

Fig. 2 - The cold test of parameters $Q_{L}, \beta, Q_{0}$ for TEM $_{006}$ mode by shifting of double grating on field spot periphery

The starting current in DRO with asymmetric ORS was estimated by experimental values of $Q_{L}(\xi)$ and $\beta(\xi)$ :

$$
I_{s t}(\xi) \sim \frac{1}{L^{2} E_{\max }^{2} \exp \left(-2 \xi^{2} / w_{0}^{2}\right) Q_{L}(\xi)(1+\beta(\xi))}
$$

It was found, that in DRO with asymmetric ORS the starting current growing more than in 1.5 times should be expected at double grating shifting of $\xi \geq 0.72 w_{0}=6.0 \mathrm{~mm}$ (Fig. 3). Note, that by double grating shifting on $\xi \geq 0.72 w_{0}$ the $E^{2}$ of resonant field on the double grating reduced in 2.8 times.

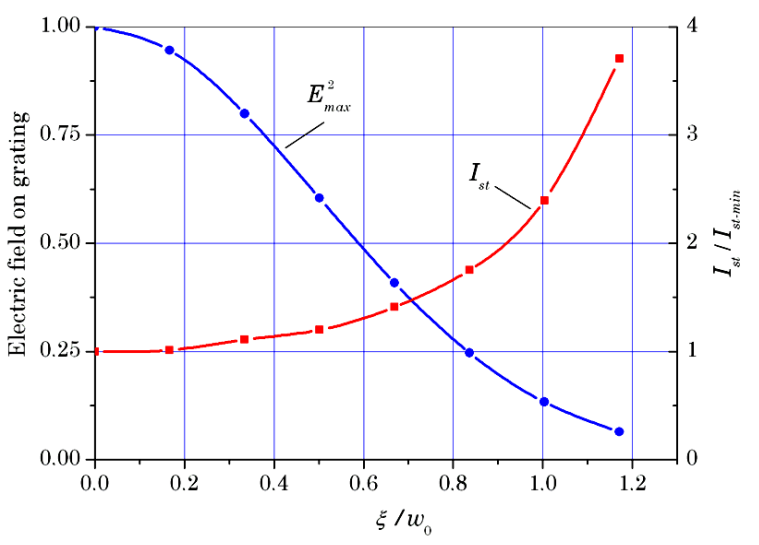

Fig. 3 - The electric field level in double grating and estimated starting current for DRO versus the double grating shift

The frequency tuning range in asymmetric ORS on $\mathrm{TEM}_{006}$-mode was investigated for the fixed values of double grating shift: $\xi=4.0 \mathrm{~mm} ; 6.0 \mathrm{~mm} ; 8.0 \mathrm{~mm}$. The Q-factor maximum was observed at the frequency $f \approx f_{\pi}$ and was increasing with the growth of double grating shifting from ORS axis (Fig.4). The frequency tuning range extension for TEM $_{006}$-mode in asymmetric ORS was observed at low-frequency region $\left(f<f_{\pi}\right)$. The maximum frequency tuning range was observed, when double grating was shifted on $\xi=6.0 \mathrm{~mm}$. In comparison with the symmetric ORS $(\xi=0)$ the frequency tuning range on $\mathrm{TEM}_{007}$-mode increased in 1.5 times at operating mode $Q$-factor $Q_{0} \geq 3000$.

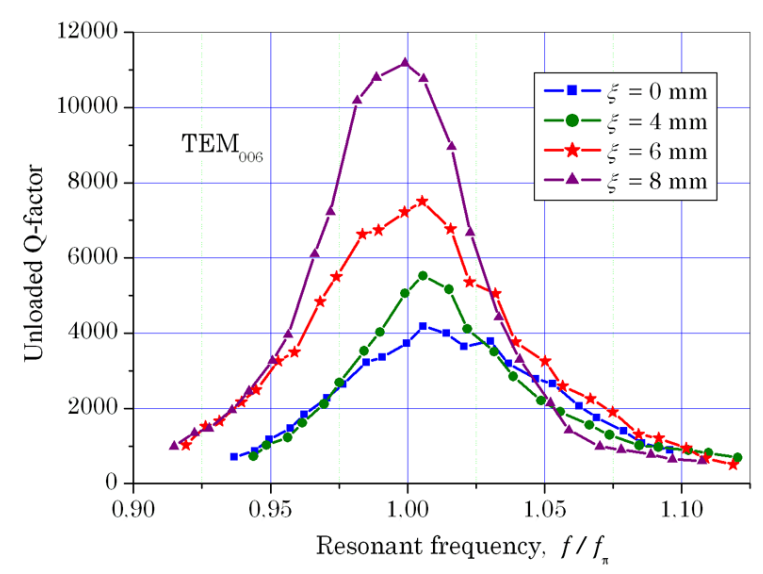

Fig. 4 - The frequency tuning range extending in asymmetric ORS at operation on TEM O066-mode

The frequency tuning range extension to lowfrequency region $\left(f<f_{\pi}\right)$ was also observed on the operating on TEM 004 -mode in asymmetric ORS (Fig. 5). Also, there were observed irregularities in the Q-factor throughout frequency tuning range by operating on TEM 005 -mode, that were caused by modes degeneration near semiconfocal geometry of ORS at $D \approx 0.5 R_{s p h}$.

\section{DYNAMICS OF RESONANT FIELD CHANGES IN ORS THROUGHOUT FREQUENCY TUNING RANGE}

The physical reason of the frequency tuning range extension in asymmetric ORS was established by the 


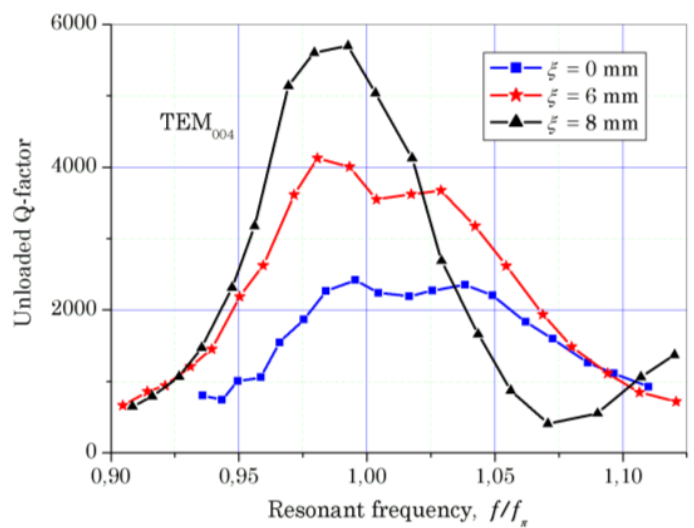

Fig. 5 - The frequency tuning range extending in asymmetric ORS at operation on TEMo04-mode

field analysis of the $\mathrm{TEM}_{006}$-mode in the 2-D hemicylindrical OR model, in which the double grating was simulated by rectangular groove with the width $a$ and depth $b$ on the flat mirror. The rectangular groove converts a flat mirror into two level reflection surface. For the case of E-polarization for resonant field (at significant wave prolongation in the rectangular groove) the properties of ORS resonant modes, that are excited in 2-D model, are close to the resonant mode properties in 3-D ORS with double grating [17]. The aperture and curvature of the mirrors in 2-D model corresponded with the 3-D ORS parameters. The rectangular groove sizes were: $a=5.40 \mathrm{~mm}: b=8.00 \mathrm{~mm}$. The rectangular groove displacement from ORS longitudinal axis was: $\xi=6.0 \mathrm{~mm}$. Calculated "half-wave" frequency for $2-\mathrm{D}$ model was $f_{\pi}=33.52 \mathrm{GHz}$. The obtained results of resonant field distributions for TEM $_{006}$-mode in symmetric and asymmetric ORS in case of E-polarization $(\boldsymbol{E} \| O Y)$ are shown on Fig.6. The excitation source was a line of current, placed in the rectangular groove at $z=-0.5 b$.

The obtained E-component field distribution for TEM ${ }_{006}$-mode demonstrates significant differences in mechanism of resonant field formation in symmetric ORS and asymmetric ORS. At the "half-wave" frequency $\left(f=f_{\pi}\right)$ the rectangular groove doesn't disturb the

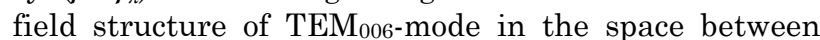
mirrors and doesn't add significant diffraction loss both in symmetric ORS and in asymmetric ORS. At the tuning down through the frequency $\left(f=0.97 f_{\pi} ; f=0.94 f_{\pi}\right)$ in symmetric ORS the outgoing field from the groove destroys the resonant field structure, that leads to fast growth of diffraction loss (Fig. 6, left). In the asymmetric ORS at the frequency tuning down the outgoing field from the groove just shifts the resonant field in the space between the mirrors without field destruction and without considerable increasing of diffraction loss (Fig. 6, right)

The comparison of theoretical results for $E_{y}$-distribution near the flat mirror and the experimental data, obtained by the probe method, are presented on Fig. 7. As a probe the conducting sphere with diameter $\varnothing 1.5 \mathrm{~mm}$ was used, the field amplitude had been defined by resonant frequency shift according to equation (5). The plane for field analysis was spaced from flat mirror surface on $d z=0.25 \lambda=2.2 \mathrm{~mm}$. The maximum shift of the frequency, caused by the probe, was $\left|f-f_{q}\right|=(40 \div 80) \mathrm{MHz}$, that allowed to measure the resonant field amplitude up to $0.05 E_{\max }$.
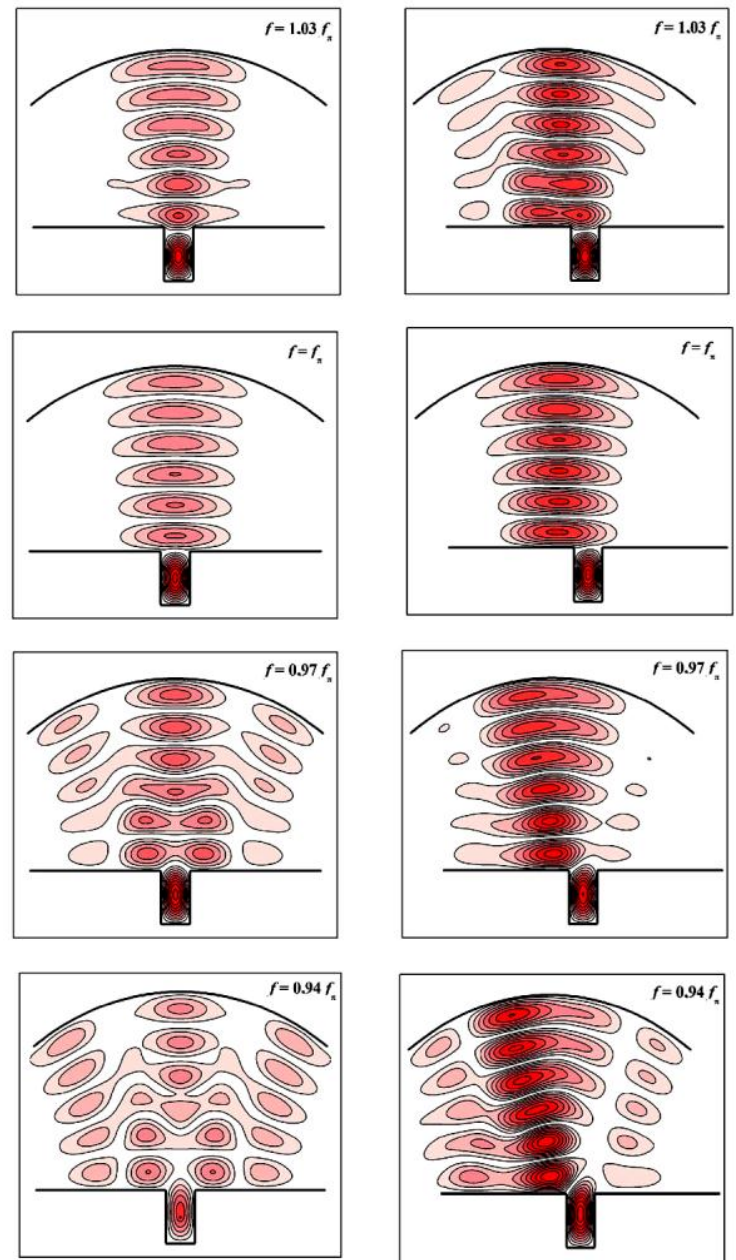

Fig. 6 - The resonant field structure changes for TEM ${ }_{006}$-mode throughout the frequency tuning range in symmetric ORS (left) and asymmetric ORS (right). The lines of equal field amplitude are plotted with discrete $0.1 E_{\max }$

The experimental results of the resonant field distribution are in good agreement with the obtained data by the 2-D model both for symmetric and asymmetric ORS (Fig. 7). At the resonant frequency $f=f_{\pi}$, corresponding to phase matching of double grating with resonant field, the $E$-component distribution near the flat mirror in symmetric and asymmetric ORS has Gaussian character with small field amplitude on the flat mirror edges. At the detuning from $f_{\pi}$, both towards the higher frequencies $\left(f=1.03 f_{\pi}\right)$, and to low frequency region $\left(f=0.97 f_{\pi}\right.$; $\left.f=0.94 f_{\pi}\right)$ the field amplitude growth on the edges of the flat mirror is observed. It leads to the $\mathrm{Q}$-factor

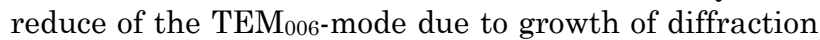
loss for symmetric ORS and for asymmetric ORS. However, if for symmetric ORS on frequencies $f=0.97 f_{\pi}$, $f=0.94 f_{\pi}$ it occurs a bifurcation of central field spot and there appear additional variations of resonant field near the edges of mirrors, so in asymmetric ORS only shifting of resonant field from longitudinal axis $(O Z)$ is observed. 

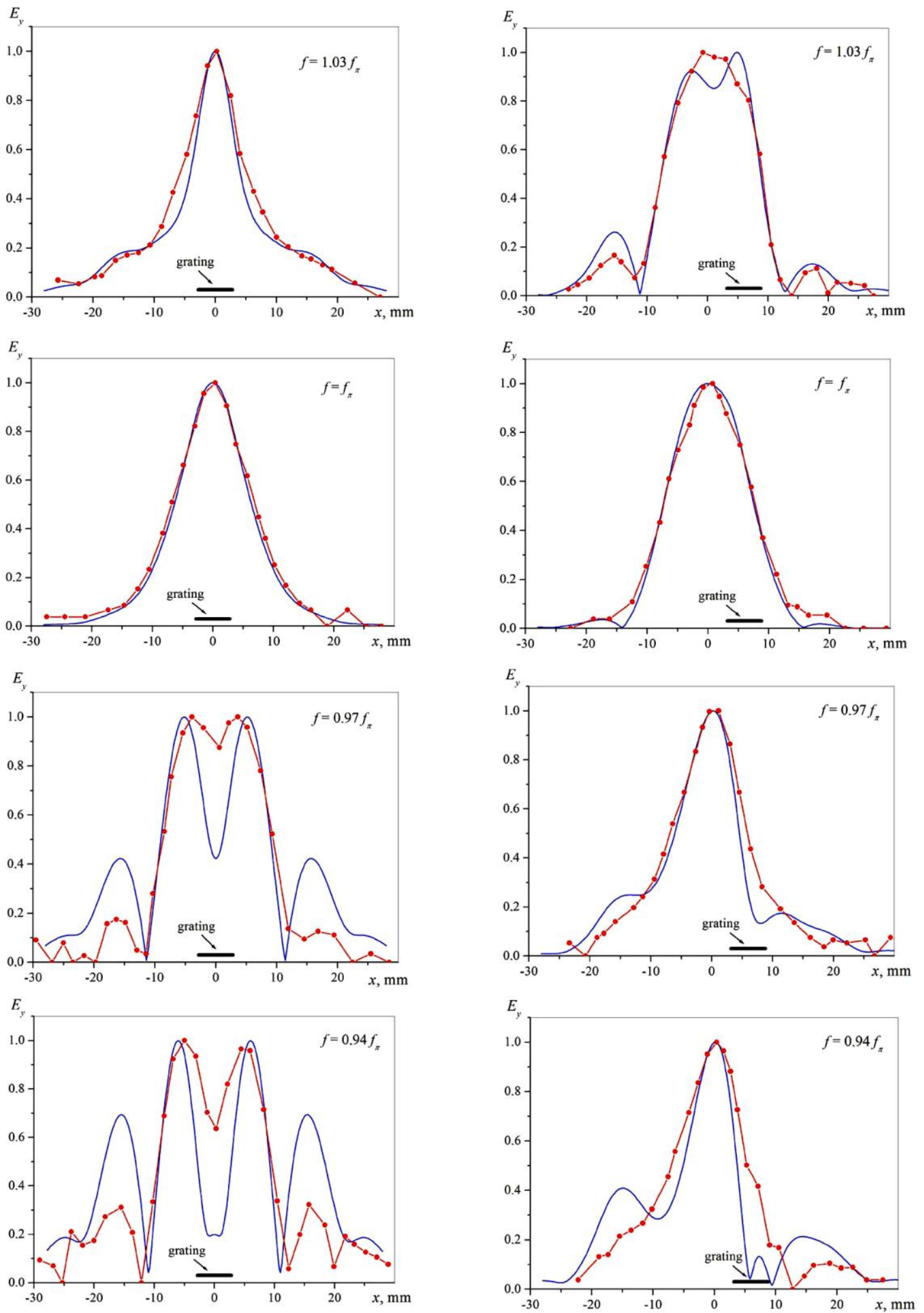

Fig. 7 - Distribution of $E_{y}$-component of TEM 007 -mode field near the flat mirror on several frequencies in symmetric ORS (left) and in asymmetric ORS (right): — theory; —- experiment 
Note, that the probe measurements showed lower resonant field level on the edges of the mirrors, than it occurs in the 2-D model of the ORS. The reason of such difference probably is caused by that the rectangular groove makes a stronger perturbation to the resonant field, than the double grating.

\section{CONCLUSION}

1. In the present paper a new type of ORS for DRO is suggested, in which the periodic structure in double grating form is shifted to field spot periphery of TEMo0q-mode.

2. The asymmetric displacement of double grating on the ORS mirror reduces its destructive influence on the resonant field formation and reduces ohmic loss of resonant mode. It provides increasing of $\mathrm{Q}$-factor and extends the single-mode frequency tuning range in asymmetric ORS.

3. It is suggested the choice technique for the optimal shift of double grating on the flat mirror from ORS axis, provided the maximum of single-mode frequency tuning in DRO with asymmetric ORS without significant growth of the oscillation starting current.

4. The experimental investigations of asymmetric ORS and 2-D modeling of resonant fields in 8-mm waveband had been carried out, that allowed establishing the physical nature of the single-mode frequency tuning extension in asymmetric ORS.

\title{
Генератор дифракційного випромінювання з асиметричною відкритою резонансною системою. Частина 1. Результати "холодних" досліджень відкритої резонансної системи
}

\author{
В.С. Мірошниченко, Є.О. Ковальов \\ Інститут радіофізики та електроніки іл. О.Я. Усикова НАН Украӥни, \\ вул. Академіка Проскури, 12, 61085 Харків, Україна
}

\begin{abstract}
Представлені результати експериментальних досліджень та 2-D моделювання властивостей асиметричної відкритої резонансної системи для генератора дифракційного випромінювання, в якій періодична структура зміщена на периферію плями поля робочої $\mathrm{TEM}_{00 q}$-моди. Встановлено, що асиметричне розміщення періодичної структури у вигляді здвоеної гребінки на плоскому дзеркалі напівсферичного відкритого резонатора дає можливість знизити омічні та дифракційні втрати робочої ТЕМ ${ }_{00 q}$ моди та суттево розширити діапазон одномодового перестроювання по частоті. Дослідження виконані у 8-мм діапазоні довжин хвиль.
\end{abstract}

Ключові слова: Відкрита резонансна система, Генератор дифракційного випромінювання, Періодична структура, Здвоена гребінка, Міліметрові хвилі.

Генератор дифракционного излучения с асимметричной открытой резонансной системой. Часть 1. Результаты “холодных" исследований открытой резонансной системы

\author{
В.С. Мирошниченко, Е.А. Ковалев \\ Институт радиобизики и электроники ил. А.Я. Усикова НАН Украинь,, \\ ул. Акаделика Проскуры, 12, 61085 Харьков, Украина
}

\begin{abstract}
Представлены результаты экспериментальных исследований и 2-D моделирования свойств асимметричной открытой резонансной системы для генератора дифракционного излучения, в которой пе-

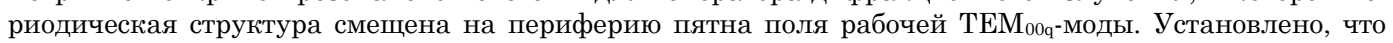
асимметричное размещение периодической структуры в виде сдвоенной гребенки на плоском зеркале полусферического открытого резонатора позволяет снизить омические и дифракционные потери рабочей $\mathrm{TEM}_{00 q}$-моды и существенно расширить диапазон одномодовой перестройки. Исследования проведены в 8-мм диапазоне длин волн.
\end{abstract}

Ключевые слова: Открытая резонансная система, Генератор дифракционного излучения, Периодическая структура, Сдвоенная гребенка, Миллиметровые волны.

\section{REFERENCES}

1. V.P. Shestopalov, Diffraction electronics (Kharkov: Vyscha shkola: 1976) [in Russian].

2. I.M. Balaklitsky, V.G. Kurin, B.K. Skrynnik, O.A. Tretyakov, V.P. Shestopalov, Pat. SU. 334605, H01J 23/16, SU, publ. 12.06.1982.

3. A.A. Vertiy, N.A. Popenko, B.K. Skrynnik, V.P. Shestopalov, Izvestiya VUZ Radiofizika 18 No 2, 1865 (1975) [in Russian].

4. Diffraction radiation generators (Ed. by V.P. Shestopalov)
(Kiev: Naukova dumka: 1991) [in Russian].

5. V.K. Korneenkov, V.S. Miroshnichenko, Radiotekhnika No 9, 28 (1997) [in Russian]

6. M.Yu. Demchenko, V.S. Miroshnichenko, Yu.V. Svishov, and Ye.B. Senkevich, Telecommunicat. Radio Eng. 67 No 7, 597 (2008).

7. T.I. Vasiljeva, I.D. Revin, Doklady AN UkrSSR, A No 7, 53 (1984).

8. P.P. Maximov, A.I. Tsvyk, V.P. Shestopalov, Trans. Higher 
School Radio Electronics 28 No 10, 59 (1985) [in Russian].

9. V.K. Koreneenkov, V.S. Miroshnichenko, B.K. Skrynnik, Telecommunicat. Radio Eng. 51 No 6-7, 144 (1997).

10. V.K. Korneenkov, V.S. Miroshnichenko, A.A. Petrushin, V.P. Shestopalov, Pat. SU. 1103745, H01J 25/00, SU, publ. 19.06.1982.

11. V.D. Yeryomka, V.S. Miroshnichenko, M.Yu. Demchenko, Pat. UA. 105215, H01J 25/00, Ukraine, publ. 25.04.2014.

12. V.S. Miroshnichenko, M.Yu. Demchenko, and Ye.B. Senkevich, Telecommunicat. Radio Eng. 73 No 1, 19 (2014).
13. V.S. Miroshnichenko, Telecommunicat. Radio Eng. 55 No 3, 40 (2001).

14. V.S. Miroshnichenko, Ye.B. Senkevich, Telecommunicat. Radio Eng. 60 No 1-2, 45 (2003).

15. V.S. Miroshnichenko, P.N. Melezhik, Ye.B. Senkevich, Tech. Phys. 51 No 8, 1076 (2006).

16. V.S. Miroshnichenko, P.N. Melezhik, Ye.B. Senkevich, Progress in Electromagnetics Research M 4, 47 (2008).

17. M.Yu. Demchenko, V.K. Korneenkov, V.S. Miroshnichenko, A.E. Poedinchuk, Yu.V. Svischov, Yu.A. Tuchkin, Telecommunicat. Radio Eng. 58 No1-2, 1 (2002). 